\title{
HLA-A, -B and -DR Allele and Haplotype Frequencies in the European American, African American, and Hispanic Populations in Dallas, Texas: Relatedness to the North American Population
}

Gökay Bozkurt

Department of Medical Genetics, Faculty of Medicine, Adnan Menderes University, Aydın, Turkey

\begin{abstract}
Objective: In the United States of America (USA) population, several studies focusing on frequencies of HLA alleles and their haplotypes have been reported, but HLA data in the USA population living in Dallas, Texas, are reported here for the first time. The aim of this study was to investigate the distribution of HLA in the populations of African American, European American, and Hispanic of Dallas, Texas and its genetic relatedness to the USA populations.

Material and Methods: We present the HLA data available from the Transplant Donor Program database of Southwestern Medical Center at the University of Texas at Dallas. The comparative study of their allele frequencies, characteristic haplotypes, genetic distances with other Americans residing in the USA is complemented by neighbor-joining dendrogram and correspondence analysis.
\end{abstract}

Results: The results of our study reflect a predominance of European and also Asian rather than African Ancestry for the Hispanic sample, especially those living in South of USA.

Conclusion: As new information, our study results show that the largest genetic distances between all USA groups were those of the African Americans compared with each of the other groups in four major races.

Key Words: African Americans, European Americans, hispanics, haplotype frequency, HLA, Dallas, Texas

Received: 05.01.2010

Accepted: 16.08.2010

\section{Introduction}

Dallas is a county located in the U.S state of Texas within the Dallas-Fort Worth-Arlington metropolitan area in north central Texas. As of July 1, 2006, the historic period in Texas including Dallas is defined by the date of contact between aboriginal groups and the Spanish explorers in the 1500s (1). Historical accounts describe that the Dallas area was inhabited by numerous Indian groups before Anglo pioneers began settling in the 1800s. However, archaeologically, Indian groups cannot be found (2). In 1846, the Republic of Texas was annexed by the U.S and Dallas County was established. Dallas has historically been predominantly European American but its population diversified as it grew in size, and Hispanics outnumbered African-Americans for the first time in the 2000 census as the largest minority group in Dallas. The reason for this may be that Dallas is a major destination for Mexican immigrants seeking opportunities in the U.S, because Texas makes up part of the U.S-Mexico border. The current racial makeup of Dallas is 48.3 percent white, 35.5 percent Hispanic (Hispanics may be of any race, so are also included in applicable race categories), 11.3 percent African American, 3.3 percent Asian, 1.0 percent from two or more races, 0.3 percent Native American (American Indian and Alaska Native), 0.2 percent some other race, and 0.1 percent Native Hawaiian and other Pacific Islander according to the census taken in 2006 (3).

In the U.S population, several studies focusing on frequencies of HLA antigens and/or alleles and their haplotypes have been reported (4-6). However, HLA alleles and haplotypes in the Dallas, Texas (TX) population have not been reported previously. In the present work, it is intended to obtain the distribution of HLA-A, -B, -DR in the populations of African American, European American, and Hispanic of Dallas, Texas for the first time, in order to estimate gene and haplotype frequencies and compare them with the U.S population.

For these purposes, we extracted and presented HLA allele and haplotype frequency data available from the Transplant Donor Program database (TDP) of Southwestern Medical Center at the University of Texas at Dallas from three major U.S. census categories of race and ethnicity. A discriminatory classification of HLA allelic variation on the basis of observed population allele frequencies (very common, common, rare and unseen) based on genotyping for $\operatorname{HLA} A, B$, and DRB1 is introduced. The comparative study of their allele frequencies, characteristic haplotypes and genetic distances with other 
Americans residing in the United States is complemented by a neighbor-joining dendrogram and correspondence analysis.

\section{Materials and Methods}

The HLA allele and haplotype frequency data was obtained from volunteer bone marrow donors from the TDP of Southwestern Medical Center at the University of Texas at Dallas. The sample represents a random sample of the entire registry. Informed consent of the donors for making the data publicly available was obtained from all individuals. HLA frequency data are presented on the basis of the three predominant US census categories for categorizing ethnic and racial groups: African Americans, European Americans and Hispanics. These categories from TDP input questionnaires define the self-described ethnic groups. 499 biologically unrelated individuals (195 African Americans, 170 European Americans, and 134 Hispanics) were extracted for presenting HLA frequency data and phylogenetic calculations. Proportionally, Dallas Hispanics samples remain represented lowest, comprising around $26.8 \%$ of the total typed samples, but a fall-off in available samples of the three minority groups is not noticeable for haplotypes.

Genotyping of HLA-A, B and DR loci was performed by means of the PCR-SSP method using micro SSP kits. This study presents the serologic equivalents of HLA-A, -B, and -DR alleles for a more direct comparison with previous literature. Since the HLA types of our samples were molecularly defined, we used the 2009 HLA Dictionary (the IMGT HLA nomenclature reports-HLADB 2.24.0, January 2009) to determine the serologic equivalents for HLA alleles.

We compared HLA-A-, -B-, and -DR allele frequencies between the Dallas population in our study and the U.S populations in the study of Maiers et al. (6). According to current literature, the recent work of Maiers et al. (2007) appears to be the study reporting the largest database of HLA-A-, -B-, and -DR typed individuals of four major races who reside in the United States: African Americans, Asians, European Americans, and Hispanics (6).

A90, B90 and DR90 were included in the estimation of gene and haplotype frequencies to represent the null alleles and the alleles which have no serologic equivalents based on the WHO assigned type presented in the IMGT HLA database at each of the respective loci. The following alleles were collapsed to A90, B90, DR90 at each of the respective loci: $B \star 8201, B * 4008 \rightarrow B 90$ in our study; and $A^{\star} 0116 N, A^{\star} 0219$, $A * 0230, A * 0253 N, A * 0260, A * 0307, A * 2305, A * 2425, A * 2426$, $A \star 2612, A * 3010, A * 3109, A * 3206, A * 3403, A * 6807, A^{\star} 6815$, $A * 6825, A * 7409, A * 7411 \rightarrow A 90, B * 0721, B * 0805, B * 0812$, $B \star 1405, B \star 1540, B * 1547, B * 1554, B * 1561, B * 1808, B * 3521$, $B \star 3522, B * 3528, B * 3914, B * 4008, B * 4012, B * 4023, B * 4040$, $B * 4418, B * 5119, B * 5137, B * 6702, B * 8202 \rightarrow B 90, D R B 1 *$ 0418，DRB1*1115，DRB1*1117，DRB1*1139，DRB1*1208, DRB1*1309, DRB1*1331, DRB1*1425, DRB1*1514 $\rightarrow$ DR90 in the study of Maiers et al.

Because of the multi-ethnic and multi-racial background of the U.S population, we carried out all the analyses for African Americans, European Americans, and Hispanics separately using an implementation of the expectation-maximization (EM) algorithm (7-9). Statistical analysis and the Hardy-Weinberg equilibrium (HWE) based on the exact test of Guo and Thompson was performed with Arlequin v3.11, a software for population genetics data analysis (Genetics and Biometry Laboratory, University of Geneva, Geneva, Switzerland), (10, 11). A phylogenetic tree (dendrogram) was constructed with the allelic frequencies by using the neighbour-joining (NJ) method (12) with the genetic distances between populations (13), by using the software DISPAN, which contained the programs GNKDST and TREEVIEW $(14,15)$. Correspondence analysis in three dimensions and its bidimensional representation was carried out by using the SSPS 15.0 for Windows (16).

\section{Results}

The frequencies of HLA-A, -B, and -DR alleles in our study population are summarized in Tables 1-3. We determined that all the groups are in HWE at all loci.

\section{Two-loci haplotype frequencies}

Table 4 shows the frequencies of the A-B haplotypes occurring at frequencies of more than 1\%. We detected 291, 209 and 230 haplotypes in Dallas African Americans, Dallas European Americans, and Dallas Hispanics, respectively, predicted by the EM algorithm.

The strength of association of two alleles from A/B loci was determined by the $D^{\prime}$ values of the haplotypes (Table 5). Interestingly, the strongest association with the highest $D^{\prime}$ and Chisquare values in both Dallas African Americans $\left(D^{\prime}=0.35100\right.$, $\left.\chi^{2}=37.01100\right)$ and Dallas European Americans $\left(D^{\prime}=0.63520\right.$, $\chi^{2}=126.88370$ ) was the same: $A 1-B 8$, but was different in Dallas Hispanics: A28-B61 ( $\left.D^{\prime}=0.40900, \chi^{2}=34.55300\right)$. The number of statistically significant $A / B$ combinations identified at frequencies higher than $1 \%$ were 6 for Dallas African Americans and 9 for Dallas European Americans and Dallas Hispanics. We found some HLA-A alleles associated with multiple HLA-B in some of our ethnic groups. 3 and 2 statistically significant HLA-A alleles associated with multiple HLA-B were identified at frequencies higher than $1 \%$ in Dallas European Americans and Dallas Hispanics, in that order.

\section{Three-locus haplotype frequencies}

The overall degree of sharing among HLA haplotypes can be obtained from Table 6. As a reflection of the overall A-BDR haplotype similarity among the three groups, we present the rank and order of haplotypes from the perspective of the 10 most common haplotypes in each group. For A-B-DR haplotypes, common alleles are defined here as those observed in the 10 most common haplotypes and rare alleles are those not present in the 10 most common haplotypes in each group.

The most common haplotype in Dallas African American sample is A2-B35-DR13, which is found in an estimated 0.020532 copies in Dallas African American sample. This haplotype is not seen in either Dallas European American or Dallas Hispanic samples at all. The only one of the ten most common A-B-DR haplotypes present in the Dallas African American sample, A2-B7-DR15, is rarely seen in Dallas His- 
Table 1. HLA-A frequencies in the African American, European American, and hispanic populations of Dallas, Texas

\begin{tabular}{|c|c|c|c|c|c|c|}
\hline \multicolumn{7}{|c|}{ Census Groups } \\
\hline \multirow[b]{2}{*}{ Rank } & \multicolumn{2}{|c|}{ African Americans } & \multicolumn{2}{|c|}{ European Americans } & \multicolumn{2}{|c|}{ Hispanics } \\
\hline & Allele & $\begin{array}{c}\text { Allele } \\
\text { frequencies }\end{array}$ & Allele & $\begin{array}{c}\text { Allele } \\
\text { frequencies }\end{array}$ & Allele & $\begin{array}{c}\text { Allele } \\
\text { frequencies }\end{array}$ \\
\hline 1 & A2 & 0.158974 & A2 & 0.308824 & A2 & 0.235075 \\
\hline 2 & A30 & 0.125641 & $\mathrm{~A} 1$ & 0.191176 & A24 & 0.152985 \\
\hline 3 & A23 & 0.123077 & A3 & 0.108824 & A68 & 0.093284 \\
\hline 4 & A68 & 0.082051 & A11 & 0.091176 & A3 & 0.082090 \\
\hline 5 & A74 & 0.076923 & A24 & 0.076471 & A11 & 0.063433 \\
\hline 6 & A3 & 0.071795 & A29 & 0.038235 & $\mathrm{~A} 1$ & 0.059701 \\
\hline 7 & A33 & 0.064103 & A23 & 0.032353 & A31 & 0.048507 \\
\hline 8 & $\mathrm{~A} 1$ & 0.058974 & A25 & 0.026471 & A29 & 0.044776 \\
\hline 9 & A34 & 0.046154 & A31 & 0.026471 & A30 & 0.041045 \\
\hline 10 & A29 & 0.033333 & $\mathrm{~A} 30$ & 0.020588 & A23 & 0.033582 \\
\hline 11 & A24 & 0.028205 & A32 & 0.017647 & A33 & 0.029851 \\
\hline 12 & A66 & 0.028205 & A26 & 0.014706 & A28 & 0.026119 \\
\hline 13 & A28 & 0.025641 & A68 & 0.014706 & A32 & 0.026119 \\
\hline 14 & A36 & 0.025641 & A33 & 0.011765 & A26 & 0.022388 \\
\hline 15 & A32 & 0.015385 & A28 & 0.008824 & A34 & 0.014925 \\
\hline 16 & A80 & 0.012821 & A66 & 0.005882 & A25 & 0.011194 \\
\hline 17 & A31 & 0.010256 & A74 & 0.002941 & A74 & 0.007463 \\
\hline 18 & A11 & 0.007692 & A80 & 0.002941 & A210 & 0.003731 \\
\hline 19 & A26 & 0.005128 & & & A36 & 0.003731 \\
\hline
\end{tabular}

panics, at rank 87. The other nine most common Dallas African American haplotypes are absent in Dallas Hispanics. Also, only two of the ten most common A-B-DR haplotypes present in the Dallas African American sample are seen in Dallas European Americans (the common Dallas European American haplotype A2-B7-DR15, the rare Dallas European American haplotype A1-B57-DR17 at rank 72.). The other eight most common Dallas African American haplotypes are absent in the Dallas European Americans.

The most common haplotype in the Dallas European American sample is A1-B8-DR17, which is found in an estimated 0.067150 copies in the Dallas European American sample, and is not seen in other two groups. Seven of the ten most common A-B-DR haplotypes present in the Dallas European American sample are seen in the other two groups. A3-B7DR15 and A29-B44-DR7 are commonly seen and A2-B44-DR4, A1-B8-DR3, A2-B15-DR4, A2-B7-DR15, and A2-B51-DR13 are rarely seen in Dallas Hispanics. On the other hand, only two of the ten most common A-B-DR haplotypes present in the Dallas European American sample are seen in Dallas African Americans as seen in Table 6 (the common Dallas African American haplotype A2-B7-DR15, the rare Dallas African American haplotype A29-B44-DR7).

The most common haplotype in the Dallas Hispanics sample is A2-B35-DR8, which is found in an estimated 0.040621

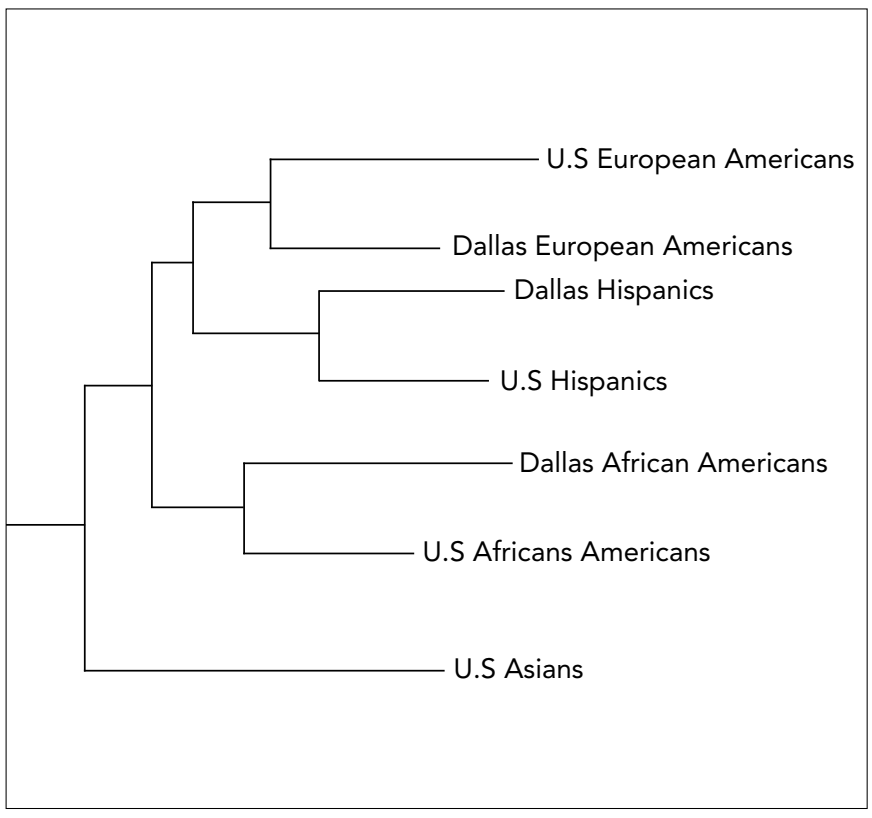

Figure 1. A global view of the relationship among Dallas and U.S populations represented by a neighbor-joining tree. The genetic distances $(\mathrm{Da})$ between populations were calculated by means of HLA A, B, DR allele frequencies. Bootstrap values from 1000 replicates are depicted 
Table 2. HLA-B frequencies in the African American, European American, and hispanic populations of Dallas, Texas

\begin{tabular}{|c|c|c|c|c|c|c|}
\hline \multirow[b]{3}{*}{ Rank } & \multicolumn{4}{|c|}{ Census Groups } & \multirow{2}{*}{\multicolumn{2}{|c|}{ Hispanics }} \\
\hline & \multicolumn{2}{|c|}{ African Americans } & \multicolumn{2}{|c|}{ European Americans } & & \\
\hline & Allele & $\begin{array}{c}\text { Allele } \\
\text { frequencies }\end{array}$ & Allele & $\begin{array}{c}\text { Allele } \\
\text { frequencies }\end{array}$ & Allele & $\begin{array}{c}\text { Allele } \\
\text { frequencies }\end{array}$ \\
\hline 1 & B53 & 0.130769 & B8 & 0.179412 & B35 & 0.156716 \\
\hline 2 & B15 & 0.089744 & B44 & 0.147059 & B39 & 0.085821 \\
\hline 3 & B35 & 0.074359 & B7 & 0.105882 & B51 & 0.067164 \\
\hline 4 & B44 & 0.064103 & B35 & 0.076471 & B44 & 0.059701 \\
\hline 5 & B58 & 0.061538 & B15 & 0.044118 & B14 & 0.055970 \\
\hline 6 & B7 & 0.061538 & B51 & 0.044118 & B40 & 0.052239 \\
\hline 7 & B42 & 0.053846 & B39 & 0.038235 & B15 & 0.044776 \\
\hline 8 & B57 & 0.046154 & B40 & 0.038235 & B18 & 0.044776 \\
\hline 9 & B8 & 0.046154 & B18 & 0.035294 & B7 & 0.041045 \\
\hline 10 & B70 & 0.041026 & B27 & 0.035294 & B61 & 0.033582 \\
\hline 11 & B45 & 0.038462 & B57 & 0.032353 & B48 & 0.029851 \\
\hline 12 & B49 & 0.038462 & B14 & 0.029412 & B52 & 0.029851 \\
\hline 13 & B81 & 0.033333 & B49 & 0.020588 & B8 & 0.029851 \\
\hline 14 & B51 & 0.028205 & B62 & 0.020588 & B57 & 0.026119 \\
\hline 15 & B18 & 0.025641 & B13 & 0.017647 & B45 & 0.022388 \\
\hline 16 & B39 & 0.017949 & B41 & 0.017647 & B50 & 0.022388 \\
\hline 17 & B52 & 0.017949 & B45 & 0.017647 & B13 & 0.018657 \\
\hline 18 & B72 & 0.017949 & B38 & 0.014706 & B27 & 0.018657 \\
\hline 19 & B14 & 0.015385 & B50 & 0.014706 & B49 & 0.018657 \\
\hline 20 & B50 & 0.015385 & B60 & 0.014706 & B38 & 0.014925 \\
\hline 21 & B27 & 0.012821 & B61 & 0.011765 & B41 & 0.014925 \\
\hline 22 & B55 & 0.012821 & B47 & 0.005882 & B56 & 0.014925 \\
\hline 23 & B13 & 0.007692 & B52 & 0.005882 & B58 & 0.014925 \\
\hline 24 & B41 & 0.007692 & B53 & 0.005882 & B62 & 0.014925 \\
\hline 25 & B63 & 0.007692 & B55 & 0.005882 & B53 & 0.011194 \\
\hline 26 & B78 & 0.007692 & B58 & 0.005882 & B37 & 0.007463 \\
\hline 27 & B37 & 0.005128 & B70 & 0.005882 & B55 & 0.007463 \\
\hline 28 & B40 & 0.005128 & B37 & 0.002941 & B60 & 0.007463 \\
\hline 29 & B38 & 0.002564 & B48 & 0.002941 & B65 & 0.007463 \\
\hline 30 & B5102 & 0.002564 & B64 & 0.002941 & B4005 & 0.003731 \\
\hline 31 & B56 & 0.002564 & & & B42 & 0.003731 \\
\hline 32 & B60 & 0.002564 & & & B63 & 0.003731 \\
\hline 33 & B62 & 0.002564 & & & B64 & 0.003731 \\
\hline 34 & B90 & 0.002564 & & & B73 & 0.003731 \\
\hline 35 & & & & & B78 & 0.003731 \\
\hline 36 & & & & & B90 & 0.003731 \\
\hline
\end{tabular}

copies in the Dallas Hispanics sample, and is entirely absent in the haplotypes of other two groups. Only one of the ten most common A-B-DR haplotypes presents in the Dallas Hispanics sample, A29-B44-DR7, and is rarely seen in Dallas African Americans. This same haplotype and A3B7-DR15 is cofigmmonly found in the Dallas European
American sample. The dendrogram obtained with the neighbor-joining method is illustrated in Figure 1. These results were confirmed in the correspondence analysis, as illustrated in Figure 2. European Americans, African Americans, Hispanics, and Asians represent genetically distinct groups. 


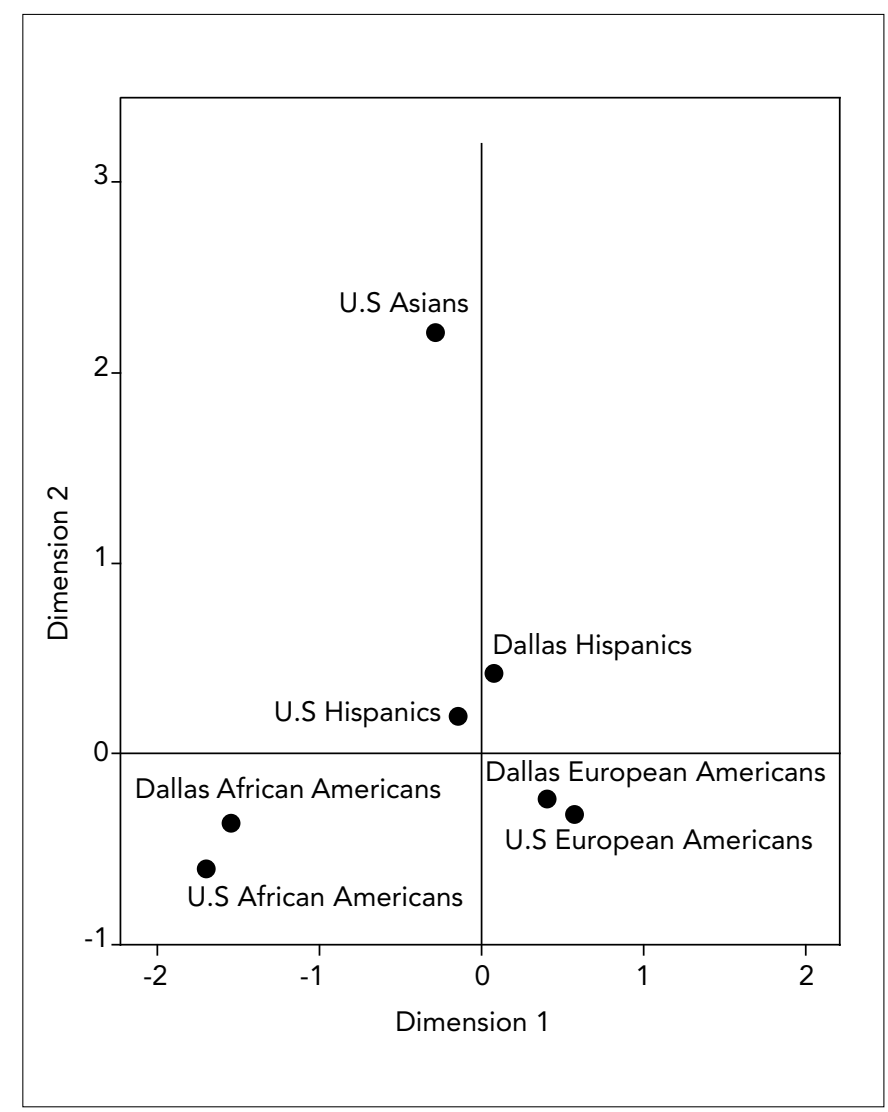

Figure 2. Bi-dimensional representation of correspondence analysis based on HLA A, B and DR allele frequencies, showing the relationship among Dallas and U.S populations

\section{Discussion}

The current study is the first to use a sample representative of the European American, African American, and Hispanic populations living in Dallas, TX, stratified by its three main ethnic groups with a depth analysis of the relationship with each other and their ancestries.

To our knowledge, the works of Mori et al. (1975) and Maiers et al. (2007) appear to report the largest database of HLA-A-, -B-, and -DR typed individuals of five major races who reside in the United States: African Americans, Asians, European Americans, Hispanics, and Native Americans, although the study of Maiers et al. does not include Native Americans $(5,6)$. HLA-A, B and DR alleles, at frequencies of up to 5 percent in the populations in our study and the populations in the previous studies conducted by Mori et al. and Maiers et al. mostly overlap.

It is reported that the Hispanic group in the United States is largely constituted of both Caribbean and Latin American populations, whose ancestries contain distinct contributions of peoples of Native American, European and African origin (6). Concerning the Dallas Hispanics sample, the HLA allele polymorphism supports the historical evidence of a predominantly European ancestry. This is because seven of ten most common HLA-A alleles present in Dallas Hispanics, HLA-A2, A24, A3, A11, A1, A31, and A29 were seen in Dallas European Americans at higher frequencies than in Dallas African Americans and contributed to $83.2 \%$ of the population gene pool. In contrast, only three alleles, A68, A30, and A23, were seen in Dallas African Americans at higher frequencies than in Dallas European Americans and contributed to $16.8 \%$ of the population

Table 3. HLA-DR frequencies in in the African American, European American, and hispanic populations of Dallas, Texas

\begin{tabular}{|lcccccc|}
\hline Rank & \multicolumn{2}{c}{ African Americans } & \multicolumn{2}{c}{ European Americans } & \multicolumn{2}{c|}{ Hispanics } \\
Allele & Alle & Allele & $\begin{array}{c}\text { Allele } \\
\text { frequencies }\end{array}$ & Allele & $\begin{array}{c}\text { Allele } \\
\text { frequencies }\end{array}$ \\
\hline 1 & DR13 & 0.176923 & DR4 & 0.188235 & DR4 & 0.264925 \\
2 & DR15 & 0.125641 & DR7 & 0.123529 & DR8 & 0.093284 \\
3 & DR11 & 0.117949 & DR17 & 0.114706 & DR14 & 0.089552 \\
4 & DR7 & 0.107692 & DR13 & 0.108824 & DR15 & 0.085821 \\
5 & DR3 & 0.094872 & DR1 & 0.091176 & DR7 & 0.078358 \\
6 & DR8 & 0.064103 & DR15 & 0.091176 & DR1 & 0.074627 \\
7 & DR12 & 0.051282 & DR3 & 0.079412 & DR11 & 0.070896 \\
8 & DR17 & 0.043590 & DR11 & 0.058824 & DR13 & 0.070896 \\
9 & DR4 & 0.043590 & DR8 & 0.050000 & DR3 & 0.059701 \\
10 & DR1 & 0.041026 & DR14 & 0.026471 & DR17 & 0.037313 \\
11 & DR9 & 0.035897 & DR12 & 0.017647 & DR16 & 0.029851 \\
12 & DR14 & 0.030769 & DR9 & 0.017647 & DR12 & 0.014925 \\
13 & DR10 & 0.025641 & DR16 & 0.011765 & DR10 & 0.011194 \\
14 & DR18 & 0.020513 & DR103 & 0.008824 & DR103 & 0.011194 \\
15 & DR16 & 0.010256 & DR10 & 0.005882 & DR90 & 0.007463 \\
16 & DR90 & 0.010256 & DR90 & 0.005882 & & \\
\hline
\end{tabular}


gene pool. The nine of ten most common HLA-B alleles present in Dallas Hispanics were seen in Dallas European Americans at higher frequencies than in Dallas African Americans and contributed to $59.7 \%$ of the population gene pool. However, only one allele, B15, is seen in Dallas African Americans at higher frequencies than in European Americans and contributed to $4.47 \%$ of the population gene pool. On the DR locus, DR4, which is the most common allele with a frequency of $26.49 \%$ in Dallas Hispanics, is also the most frequent allele with a frequency of $18.82 \%$ in Dallas European Americans. Moreover, the mean distances of Dallas Hispanics to Dallas European Americans, 0.0110, are smaller than the mean distances to Dallas African Americans, 0.0213, as expected according to the predominance of European rather than African Ancestry for Hispanics.

Some additional information about the high diversity and the interethnic admixture of our population can be inferred from the haplotype data analysis. The 162, 121, and 129 A/B combinations were identified at frequencies higher than $1 \%$ in Dallas African American, European Americans and Hispanic populations, in that order. About half of HLA-A-B haplotypes are shared between all the groups (Table 4). The statistically significant HLA-A-B haplotypes in each group are shown in Table 5 . Concerning the statistically significant HLA-A-B haplotypes shared between all the groups, A1-B8 is shared between all the groups. Additionally, two statistically significant HLA-A$B$ haplotypes, A3-B7 and A24-B39, are shared between Dallas European Americans and Dallas Hispanics. Our results confirm the well-known fact that the distributions of haplotypes varies among races, and they also reveal that certain common haplotypes are shared among all racial groups and represent an opportunity for well-matched transplants between donors and recipients of different races (17).

As mentioned in the Results section, when we evaluated the A-B-DR haplotypes shared between groups from the perspective of the 10 most common haplotypes in each group, we saw that at least one of the ten most common A-B-DR haplotypes present in any group is commonly seen in at least one of the other two groups (Table 6). Two of the ten most common A-B-DR haplotypes present in Dallas African Americans are seen in Dallas European Americans, while seven of the ten

Table 4. The frequencies of all (statistical significant and non-significant) the A-B haplotypes occurring at frequencies of more than $1 \%$ in the African American, European American, and Hispanic populations of Dallas, Texas

\begin{tabular}{|c|c|c|c|c|c|c|}
\hline \multicolumn{7}{|c|}{ Dallas racical/ethnic groups } \\
\hline \multirow[b]{2}{*}{ Rank } & \multicolumn{2}{|c|}{ African Americans } & \multicolumn{2}{|c|}{ European Americans } & \multicolumn{2}{|c|}{ Hispanics } \\
\hline & Allele & $\begin{array}{c}\text { Allele } \\
\text { frequencies }\end{array}$ & Allele & $\begin{array}{c}\text { Allele } \\
\text { frequencies }\end{array}$ & Allele & $\begin{array}{c}\text { Allele } \\
\text { frequencies }\end{array}$ \\
\hline 1 & A2 B35 & 0.031 & A1 B8 & 0.1265 & A2 B35 & 0.0746 \\
\hline 2 & A23 B15 & 0.023 & A2 B7 & 0.0441 & A24 B39 & 0.0299 \\
\hline 3 & A30 B42 & 0.023 & A2 B44 & 0.0412 & A68 B39 & 0.0224 \\
\hline 4 & A2 B53 & 0.021 & A2 B15 & 0.0353 & A24 B35 & 0.0224 \\
\hline 5 & A1 B8 & 0.018 & A2 B51 & 0.0294 & A2 B39 & 0.0224 \\
\hline 6 & A74 B53 & 0.018 & A3 B7 & 0.0294 & A3 B7 & 0.0187 \\
\hline 7 & A23 B7 & 0.015 & A2 B35 & 0.0235 & A2 B15 & 0.0187 \\
\hline 8 & A2 B7 & 0.013 & A2 B8 & 0.0206 & A2 B40 & 0.0187 \\
\hline 9 & A2 B42 & 0.013 & A3 B35 & 0.0206 & A2 B14 & 0.0187 \\
\hline 10 & A3 B53 & 0.013 & A11 B44 & 0.0176 & A68 B35 & 0.0187 \\
\hline 11 & A30 B15 & 0.013 & A11 B7 & 0.0147 & A3 B18 & 0.0187 \\
\hline 12 & A2 B15 & 0.013 & A29 B44 & 0.0147 & A11 B51 & 0.0149 \\
\hline 13 & A66 B58 & 0.013 & A1 B7 & 0.0147 & A1 B8 & 0.0149 \\
\hline 14 & A36 B53 & 0.013 & A24 B39 & 0.0118 & A24 B40 & 0.0149 \\
\hline 15 & & & A3 B44 & 0.0118 & A68 B48 & 0.0112 \\
\hline 16 & & & A1 B44 & 0.0118 & A2 B44 & 0.0112 \\
\hline 17 & & & A2 B14 & 0.0118 & A2 B18 & 0.0112 \\
\hline 18 & & & A24 B44 & 0.0118 & A2 B8 & 0.0112 \\
\hline 19 & & & A11 B35 & 0.0118 & A3 B35 & 0.0112 \\
\hline 20 & & & A2 B27 & 0.0118 & A24 B15 & 0.0112 \\
\hline 21 & & & & & A28 B61 & 0.0112 \\
\hline 22 & & & & & A29 B50 & 0.0112 \\
\hline
\end{tabular}


Table 5. The statistically significant HLA-A and -B combinations identified at frequencies higher than $1 \%$ in Dallas racial groups, with highest relative linkage disequlibrium, Chi-square and $p$ values

\begin{tabular}{|c|c|c|c|c|c|c|c|}
\hline Dallas racical/ethnic groups & Haplotypes & HF & SD & D & $D^{\prime}$ & $\chi^{2}$ & $p$ \\
\hline \multirow[t]{6}{*}{ African Americans } & A2 B35 & 0.031 & 0.009 & 0.01900 & 0.30300 & 15.21500 & 0.00000 \\
\hline & A23 B15 & 0.023 & 0.008 & 0.01200 & 0.15300 & 6.40300 & 0.01100 \\
\hline & A30 B42 & 0.023 & 0.008 & 0.01600 & 0.34600 & 18.54100 & 0.00000 \\
\hline & A1 B8 & 0.018 & 0.007 & 0.01500 & 0.35100 & 37.01100 & 0.00000 \\
\hline & A66 B58 & 0.013 & 0.006 & 0.01100 & 0.41900 & 30.27300 & 0.00000 \\
\hline & A36 B53 & 0.013 & 0.006 & 0.00900 & 0.42500 & 12.30900 & 0.00000 \\
\hline \multirow[t]{9}{*}{ European Americans } & A1 B8 & 0.1265 & 0.0181 & 0.09220 & 0.63520 & 126.88370 & 0.00000 \\
\hline & A2 B15 & 0.0353 & 0.0100 & 0.02170 & 0.71060 & 17.73630 & 0.00000 \\
\hline & A2 B51 & 0.0294 & 0.0092 & 0.01580 & 0.51770 & 9.41400 & 0.00220 \\
\hline & A3 B7 & 0.0294 & 0.0092 & 0.01790 & 0.18960 & 11.85110 & 0.00060 \\
\hline & A2 B8 & 0.0206 & 0.0077 & -0.03480 & -0.62840 & 13.11650 & 0.00030 \\
\hline & A3 B35 & 0.0206 & 0.0077 & 0.01230 & 0.18000 & 7.46940 & 0.00630 \\
\hline & A29 B44 & 0.0147 & 0.0065 & 0.00910 & 0.27850 & 6.08130 & 0.01370 \\
\hline & A24 B39 & 0.0118 & 0.0059 & 0.00880 & 0.25040 & 10.23260 & 0.00140 \\
\hline & A1 B44 & 0.0118 & 0.0059 & -0.01630 & -0.58150 & 4.68590 & 0.03040 \\
\hline \multirow[t]{9}{*}{ Hispanics } & A2 B35 & 0.0746 & 0.0161 & 0.03800 & 0.31500 & 16.10300 & 0.00000 \\
\hline & A24 B39 & 0.0299 & 0.0104 & 0.01700 & 0.23000 & 7.37100 & 0.00000 \\
\hline & A68 B39 & 0.0224 & 0.0091 & 0.01400 & 0.18500 & 8.35400 & 0.00400 \\
\hline & A3 B7 & 0.0187 & 0.0083 & 0.01500 & 0.40600 & 21.11800 & 0.00000 \\
\hline & A3 B18 & 0.0187 & 0.0083 & 0.01500 & 0.36400 & 18.66300 & 0.00000 \\
\hline & A1 B8 & 0.0149 & 0.0074 & 0.01300 & 0.46800 & 28.47700 & 0.00000 \\
\hline & A68 B48 & 0.0112 & 0.0064 & 0.00800 & 0.31100 & 7.73700 & 0.00500 \\
\hline & A28 B61 & 0.0112 & 0.0064 & 0.01000 & 0.40900 & 34.55300 & 0.00000 \\
\hline & A29 B50 & 0.0112 & 0.0064 & 0.01000 & 0.47700 & 29.73600 & 0.00000 \\
\hline
\end{tabular}

most common A-B-DR haplotypes present in Dallas European American sample are seen in Dallas Hispanics. These results again support the historical evidence of a predominantly European ancestry for Dallas Hispanics sample and represent an opportunity for well-matched transplants between donors and recipients of different races. Nine of the ten most frequent haplotypes in the Dallas African American sample are not found in the ten most frequent haplotypes reported by Maiers et al. in the U.S African Americans. However, Dallas African Americans showed the closest genetic distance values with the U.S African Americans.

Bertoni et al. investigated the effect of gene flow on Hispanic populations from different geographic regions of the United States, using six autosomal DNA markers (LDLR, GYPA, HBGG, D7S8, GC, and HLA-DQA). They concluded that the U.S Hispanic populations showed different ancestral contributions, from a trihybrid structure with European, Native American, and African contributions (California, Nevada, Florida, New Jersey, and Virginia) to a dihybrid structure with European and American contributions (Southwest population) or
European and African contributions (Pennsylvania and Southeast population), according to the region of sampling (18). Our data analysis reflects a predominance of European and Asian rather than African Ancestry for the Hispanic sample, especially those living in the Southern region of the U.S because the Hispanic sample from Dallas, TX is closer to the U.S Asian than to the U.S Hispanics group. The HLA dendrogram (Fig. 1) and correspondence analysis (Fig. 2) show how close Hispanics are genetically to Europeans, and also to Asian rather than African Americans.

Our study has several limitations. The first of the major limitations of our study is the reduction to broad serologic types. It was explained in the 2009 HLA Dictionary (the IMGT HLA nomenclature reports-HLADB 2.24.0, January 2009), for example, how broad types and serologic splits. Second, our study populations did not include other ethnic groups. For example, if the "Hispanic" population sample had been compared to Amerindian populations, the conclusion may have been that the ancestry is predominantly European and Amerindian. However, these limitations could not rule out our find- 
Table 6. Occurrences of the first 10 A-B-DR frequency-ranked haplotypes for each census group in each of the other two groups for A-B-DR haplotypes, common alleles are defined here as those observed in the 10 most common haplotypes and rare alleles are not those present in the 10 most common haplotypes in each group in the text

\begin{tabular}{|c|c|c|c|c|c|c|c|c|c|c|}
\hline \multicolumn{11}{|c|}{ Dallas racical/ethnic groups } \\
\hline \multirow[t]{2}{*}{$\begin{array}{l}\text { Dallas racical/ } \\
\text { ethnic groups }\end{array}$} & \multirow[b]{2}{*}{ Rank } & \multicolumn{3}{|c|}{ Haplotype } & \multicolumn{2}{|c|}{$\begin{array}{c}\text { African } \\
\text { Americans }\end{array}$} & \multicolumn{2}{|c|}{$\begin{array}{l}\text { European } \\
\text { Americans }\end{array}$} & \multicolumn{2}{|c|}{ Hispanics } \\
\hline & & A & B & DR & Rank & Count & Rank & Count & Rank & Count \\
\hline \multirow{10}{*}{$\begin{array}{l}\text { Dallas African } \\
\text { Americans }\end{array}$} & 1 & A2 & B35 & DR13 & 1 & 0.020532 & none & 0 & none & 0 \\
\hline & 2 & A2 & B53 & DR8 & 2 & 0.017949 & none & 0 & none & 0 \\
\hline & 3 & A23 & B15 & DR15 & 3 & 0.012821 & none & 0 & none & 0 \\
\hline & 4 & A34 & B44 & DR15 & 4 & 0.012821 & none & 0 & none & 0 \\
\hline & 5 & A74 & B53 & DR13 & 5 & 0.012821 & none & 0 & none & 0 \\
\hline & 6 & $\mathrm{~A} 1$ & B57 & DR17 & 6 & 0.010256 & 72 & 0.002941 & none & 0 \\
\hline & 7 & A2 & B7 & DR15 & 7 & 0.010256 & 6 & 0.019376 & 87 & 0.003731 \\
\hline & 8 & $\mathrm{~A} 30$ & B42 & DR11 & 8 & 0.010256 & none & 0 & none & 0 \\
\hline & 9 & A68 & B15 & DR3 & 9 & 0.010256 & none & 0 & none & 0 \\
\hline & 10 & $\mathrm{~A} 2$ & B53 & DR3 & 10 & 0.010237 & none & 0 & none & 0 \\
\hline \multirow{10}{*}{$\begin{array}{l}\text { Dallas European } \\
\text { Americans }\end{array}$} & 1 & A1 & B8 & DR17 & none & 0 & 1 & 0.067150 & none & 0 \\
\hline & 2 & $\mathrm{~A} 2$ & B44 & DR4 & none & 0 & 2 & 0.040175 & 24 & 0.007463 \\
\hline & 3 & A1 & B8 & DR3 & none & 0 & 3 & 0.038235 & 17 & 0.007463 \\
\hline & 4 & A3 & B7 & DR15 & none & 0 & 4 & 0.026471 & 9 & 0.014925 \\
\hline & 5 & $\mathrm{~A} 2$ & B15 & DR4 & none & 0 & 5 & 0.023529 & 11 & 0.011194 \\
\hline & 6 & $\mathrm{~A} 2$ & B7 & DR15 & 7 & 0.010256 & 6 & 0.019376 & 87 & 0.003731 \\
\hline & 7 & $\mathrm{~A} 1$ & B44 & DR15 & none & 0 & 7 & 0.014706 & none & 0 \\
\hline & 8 & $\mathrm{~A} 2$ & B51 & DR13 & none & 0 & 8 & 0.014706 & 26 & 0.007463 \\
\hline & 9 & $\mathrm{~A} 29$ & B44 & DR7 & 16 & 0.007692 & 9 & 0.014706 & 4 & 0.018657 \\
\hline & 10 & $\mathrm{~A} 2$ & B44 & DR1 & none & 0 & 10 & 0.012495 & none & 0 \\
\hline \multirow[t]{10}{*}{ Dallas Hispanics } & 1 & $\mathrm{~A} 2$ & B35 & DR8 & none & 0 & none & 0 & 1 & 0.040621 \\
\hline & 2 & $\mathrm{~A} 2$ & B39 & DR4 & none & 0 & none & 0 & 2 & 0.026119 \\
\hline & 3 & A24 & B35 & DR4 & none & 0 & none & 0 & 3 & 0.022811 \\
\hline & 4 & A29 & B44 & DR7 & 16 & 0.007692 & 9 & 0.014706 & 4 & 0.018657 \\
\hline & 5 & A3 & B18 & DR4 & none & 0 & none & 0 & 5 & 0.018657 \\
\hline & 6 & A24 & B40 & DR4 & none & 0 & none & 0 & 6 & 0.018233 \\
\hline & 7 & A24 & B39 & DR14 & none & 0 & none & 0 & 7 & 0.014925 \\
\hline & 8 & A24 & B39 & DR4 & none & 0 & none & 0 & 8 & 0.014925 \\
\hline & 9 & $\mathrm{~A} 3$ & B7 & DR15 & none & 0 & 4 & 0.026471 & 9 & 0.014925 \\
\hline & 10 & A68 & B39 & DR4 & none & 0 & none & 0 & 10 & 0.014925 \\
\hline
\end{tabular}

ing suggesting that Hispanics are genetically closer to Asians than African Americans.

As new information, our results show that the largest genetic distances between all U.S. groups were those of the African Americans compared with each of the other groups in the four major races (African Americans, Asians, European Americans, Hispanics) who reside in the United States. In contrast to this finding, Cao et al. reported that the largest genetic distances to all U.S. groups were those of the Asians compared with each of the other groups in their study of a large data- base of HLA-A, $-B$, and $-C$ typed individuals of the five major races of U.S: African Americans, Asians, European Americans, Hispanics, and Native Americans (4). Mori et al., in their study with the largest population size, also found that Asians are the most genetically distinct group of all U.S. groups including Native Americans (4). This finding was reported as the one of the major conclusions in both studies. It could be argued that HLA information obtained at low resolution level and from a local area in our study has very limited use in biomedical or anthropological studies. However, it should be considered that 
HLA data in the study of Mori et al. were also obtained at a low resolution level. Morever, HLA information in the study with the largest population size of Maiers et al. supporting our finding were obtained at a high resolution level and not from a local area. For this reason, our finding also reflects the importance of local area studies in population genetics. Local area studies could provide different findings regarding well-known facts, even previous studies that were applied in a larger area, population size, and resolution level. It could be explained that allele and haplotype distribution in the HLA system differ from one ethnic group to another or between the members of the same ethnic group living in different geographic areas, as shown in previous studies (19).

The present study is the first investigation of the HLA status of the European American, African American, and Hispanic populations in Dallas, TX. All the groups shared the most common haplotypes, many of them frequently. These results support the concept that substantial gene flow has taken place among the four major U.S. census categories of race and ethnicity: African Americans, European Americans, Asians and Hispanics, now all comprising constituents of the United States population as a whole, as previously reported (6), or similarities can be explained by the common origin of human beings.

This knowledge will be useful in biomedical and anthropological studies and will contribute to correct interpretations of variations in HLA associations among the main ethnic groups at the population level.

\section{Acknowledgements}

We thank Peter Stastny (Prof. Dr. Graduate School of Biomedical Sciences/Southwestern Medical School, Internal Medicine-Transplant Immunology/Texas University) for contributions to project management and data collection.

\section{Conflict of Interest}

No conflict of interest was declared by the authors.

\section{References}

1. U.S. Census Bureau: State \& County QuickFacts [homepage on the internet]. c2009 [ up-dated 2009 Feb 20; cited 2009 Feb 27]. Available from www. quickfacts.census.gov/qfd/states/48000.html.

2. Legacies: A History Journal for Dallas and North Central Texas, Volume 03, Number 02, fall, 1991. Dallas Historical Society, Legacies: a History Journal for Dallas and North Central Texas, http:// texashistory.unt.edu/permalink/meta-pth-35119
3. U.S. Census Bureau: 2005-2007 American Community Survey, Data Profile, Texas [homepage on the internet]. c2009 [updated 2009 Feb 20; cited 2009 March 01]. Available from http://factfinder.census.gov/servlet/ADPTable?_bm=y\&-geo_id=04000US48\&-context $=$ adp\&-ds_name=ACS_2007_3YR_G00_\&-tree_id=3307\&lang $=$ en\&-caller $=$ geoselect $\&$-format $=$

4. Cao K, Hollenbach J, Shi X, Shi W, Chopek M, Fernandez-Vina MA. Analysis of the frequencies of HLA-A, B, and C alleles and haplotypes in the five major ethnic groups of the United States reveals high levels of diversity in these loci and contrasting distribution patterns in these populations. Hum Immunol 2001:62:1009-30. [CrossRef]

5. Mori M, Beatty PG, Graves M, Boucher KM, Milford EL. HLA gene and haplotype frequencies in the North American population: the National Marrow Donor Program Donor Registry. Transplantation 1997;64:1017-27. [CrossRef]

6. Maiers M, Gragert L, Klitz W. High-resolution HLA alleles and haplotypes in the United States population. Human Immunology 2007;68:779-88. [CrossRef]

7. Tan JM, Zhou YC, Tang XD. The technology and clinical application of tissue matching. Beijing: People's Medical Publishing House; 2002.

8. Dempster AP, Laird NM, Rubin DB. Maximum likelihood from incomplete data via the EM algorithm. J R Stat Soc B 1977;39:1.

9. Long JC, Williams RC, Urbanek M. An E-M algorithm and testing strategy for multiple-locus haplotypes. Am J Hum Genet 1995; 56:799-810.

10. Excoffier L, Laval G, Schneider S. Arlequin (version 3.0): an integrated software package for population genetics data analysis. Evol Bioinform Online 2007;1:47-50.

11. Guo SW, Thompson EA. Performing the exact test of Hardy-Weinberg proportion for multiple alleles. Biometrics 1992;48: 361-72. [CrossRef]

12. Saitou N, Nei M. The neighbor-joining method: a new method for reconstructing phylogenetic trees. Mol Biol Evol 1987:4:406-25.

13. Nei M. Phylogenetic Analysis In Molecular Evolutionary Genetics. Annu. Rev. Genet. 1996. 30:371-403. [CrossRef]

14. Nei M. Analysis of gene diversity in subdivided populations. Proc Natl Acad Sci old U. S.A. 1973:70:3321-3.

15. Nei M, Tajima F, Tateno Y. Accuracy of estimated phylogenetic trees from molecular data. J Mol Evol 1983:19:153-70. [CrossRef]

16. SPSS for Windows, Rel. 11.0.1. 2001. Chicago: SPSS Inc.

17. Zachary AA, Steinberg AG, Bias WB, Leffell MS. The frequencies of HLA alleles and haplotypes and their distribution among donors and renal patients in the UNOS registry. Transplantation. 1996;62:272-83. [CrossRef]

18. Bertoni B, Budowle B, Sans M, Barton SA, Chakraborty R. Admixture in Hispanics: distribution of ancestral population contributions in the Continental United States. Hum Biol 2003;75:1-11. [CrossRef]

19. Shen C, Zhu B, Liu M, Li S. Genetic polymorphisms at HLA-A, -B, and -DRB1 loci in Han population of Xi'an city in China. Croat Med J 2008;49:476-82. [CrossRef] 